\title{
A new predaceous midge of the Palpomyia tibialis group from northeastern Argentina (Diptera: Ceratopogonidae)
}

\author{
Gustavo R. Spinelli \& Carla G. Cazorla \\ Departamento Científico de Entomología, Museo de La Plata, Paseo del Bosque s/n, 1900 La Plata, Argentina; \\ spinelli@museo.fcnym.unlp.edu.ar
}

Received 17-IX-2002. ～Corrected 16-IX-2005. ～Accepted 15-III-2006.

\begin{abstract}
Palpomyia iberaensis n. sp., was collected by Malaise trap in the province of Corrientes, Argentina and its female and attached male genitalia are described and illustrated. The species is distinguished by the following combination of characters: females with dark brown legs except fore trochanter, basal $1 / 2$ of fore femur, basal 2/3 of mid femur, fore and mid tibiae except extreme tip, yellowish brown; fore femur with four to five, mid femur with two ventral spines; abdomen lacking gland rods. Males with gonocoxite stout, with a conspicuous posteromesal pointed hook; gonostylus short, curved; parameres entirely divided, the distal portions slender with two posteriorly directed processes. This species is placed in the tibialis group in spite of the curious parameres without recurved tips. The species is compared with its congener Palpomyia mellichroa, from southeastern Brazil. Rev. Biol. Trop. 54 (3): 1067-1070. Epub 2006 Sept. 29.
\end{abstract}

Key words: Palpomyia tibialis group, Palpomyia iberaensis n. sp., Diptera, Ceratopogonidae, taxonomy.

The genus Palpomyia Meigen 1818, worldwide in distribution, includes predaceous midges that are relatively common inhabitants of aquatic and semiaquatic environments (Grogan and Wirth 1979). Borkent and Wirth (1997) in their world catalog of Ceratopogonidae listed 234 extant species, of which 75 inhabit the New World, and Borkent and Spinelli (2000) listed 48 species for the Neotropical region.

Grogan and Wirth (1979) reviewed Palpomyia in the Nearctic region and also discussed larval and adult biology, zoogeography, economic importance as well as phylogenetic relationships within the genus and to its sister genus, Pachyhelea Wirth 1959. The most recent paper dealing with Neotropical species was one by Lane (1960), in which 33 of the 48 Neotropical species considered by Borkent and Spinelli (2000) were included in a key. According to Grogan and Wirth (1979) the four species groups of Palpomyia are apparently represented in the Neotropical region.

The study of a female of Palpomyia with attached male genitalia, that was recently collected in the province of Corrientes, Argentina, reveals that it belongs to an unnamed species, which is herein described and illustrated.

\section{MATERIALS AND METHODS}

This specimen was slide-mounted in Canada balsam and examined, measured and drawn using a binocular compound microscope with attached camera lucida. The holotype is deposited in the collection of the Department of Entomology, Museo de la Plata, Argentina (MLPA). For general ceratopogonid terminology see Downes and Wirth (1981); for Palpomyia species groups diagnoses see Grogan and Wirth (1979). 
RESULTS

Palpomyia iberaensis n. sp.

(Fig. 1-8)

Diagnosis: A large-sized species of the Palpomyia tibialis group distinguished by the following combination of characters: females with dark brown legs except fore trochanter, basal $1 / 2$ of fore femur, basal $2 / 3$ of mid femur, fore and mid tibiae except extreme tip, yellowish brown; fore femur with four to five, mid femur with two ventral spines; abdomen lacking gland rods. Males with gonocoxite stout, with a conspicuous posteromesal pointed hook; gonostylus short, curved; parameres entirely divided, the distal portions slender with two posteriorly directed processes.

Description of the female: Head. Golden brown. Eyes bare, V-shaped separation for a minimum distance equal to diameter of two ommatidia. Clypeus with about 40 slender setae. Antenna with scape pale brown, bearing five setae; pedicel dark brown; flagellum (Fig. 1) with eight proximal flagellomeres pale basally, their distal portion and flagellomeres 913 dark brown; AR 1.42. Palpus (Fig. 2) short, dark brown; third segment with a few scattered sensilla. Mandible with 12-13 stout teeth.

Thorax. Scutum dark brown, with lateral broad and irregular golden brown bands; frontal tubercle short, blunt; four prealar setae; scutellum golden brown, with eight setae; postscutellum dark brown; pleura golden brown except katepisternum and katergite, dark brown. Legs dark brown; fore trochanter, basal $1 / 2$ of fore femur, basal 2/3 of mid femur, fore and mid tibiae except extreme tip, yellowish brown; tarsi yellowish; fore femur with four to five, mid femur with two ventral spines; hind tarsal ratio 3.00; fifth tarsomeres (Fig. 3) with two sublateral rows of four to five stout setae; claws with small basal inner tooth, hind claws enlarged, larger than mid claws, the latter slightly longer than fore claws. Wing (Fig. 4) hyaline, anterior veins yellowish; wing length $3.40 \mathrm{~mm}$, breadth 1.00 mm; CR 0.82. Halter pale yellowish.
Abdomen: Pale brown in the $\mathrm{KOH}$ treated specimen; no trace of gland rods. Genitalia as in Fig. 5. Sternite eight pilose, with shallow, broad posteromedial excavation; sternite nine moderately sclerotized, each arm divided in two portions, the basal one slender and mesally directed, the apical one broader and posteriorly directed; sternite 10 with anterior margin deeply concave, with four to five pairs of large setae. Two ovoid, unequal spermathecae with very short necks, measuring 1.32 by $1.16 \mathrm{~mm}$ and 1.10 by 1.00 $\mathrm{mm}$, plus a much smaller rudimentary third, measuring 0.040 by $0.036 \mathrm{~mm}$ (Fig. 6).

Male genitalia (Fig. 7-8): Sternite nine 2.2 times broader than long, with deep, rounded posteromedial excavation, ventral surface spiculate; tergite nine short, with anterior margin broadly concave, posterior margin rounded with five setae, cercus long, bluntly rounded, each one with a pair of apical setae. Gonocoxite stout, 1.65 times longer than broad, mesal inner margin with small pointed process, conspicuous posteromesal pointed hook; a weakly sclerotized, narrow cross bar joining gonocoxites anteriorly; gonostylus short, curved, abruptly tapering at mid portion, tip pointed. Aedeagus heavily sclerotized, 1.5 times broader than its length, membrane spiculate; basal arms slender, deeply curved; basal arch extending 0.55 of total length; distal portion tapering to broad crescent-shaped tip. Parameres (Fig. 8) divided, each with recurved, strongly sclerotized basal arm; distal portion slender, swollen at mid length, with two posteriorly directed processes, the inner one small, blunt, the outer one long, slender; swollen portion and posterior processes lightly sclerotized.

Distribution: Known only from the typelocality in the province of Corrientes, Argentina.

Holotype female (with male genitalia attached): Argentina, Corrientes, Colonia Pellegrini, 1/7-XII-2001, M.C. Coscarón, Malaise trap.

Etymology: The specific epithet refers to the Ibera lagoon, a wetland located in the province of Corrientes, one of the largest such areas in Argentina. 

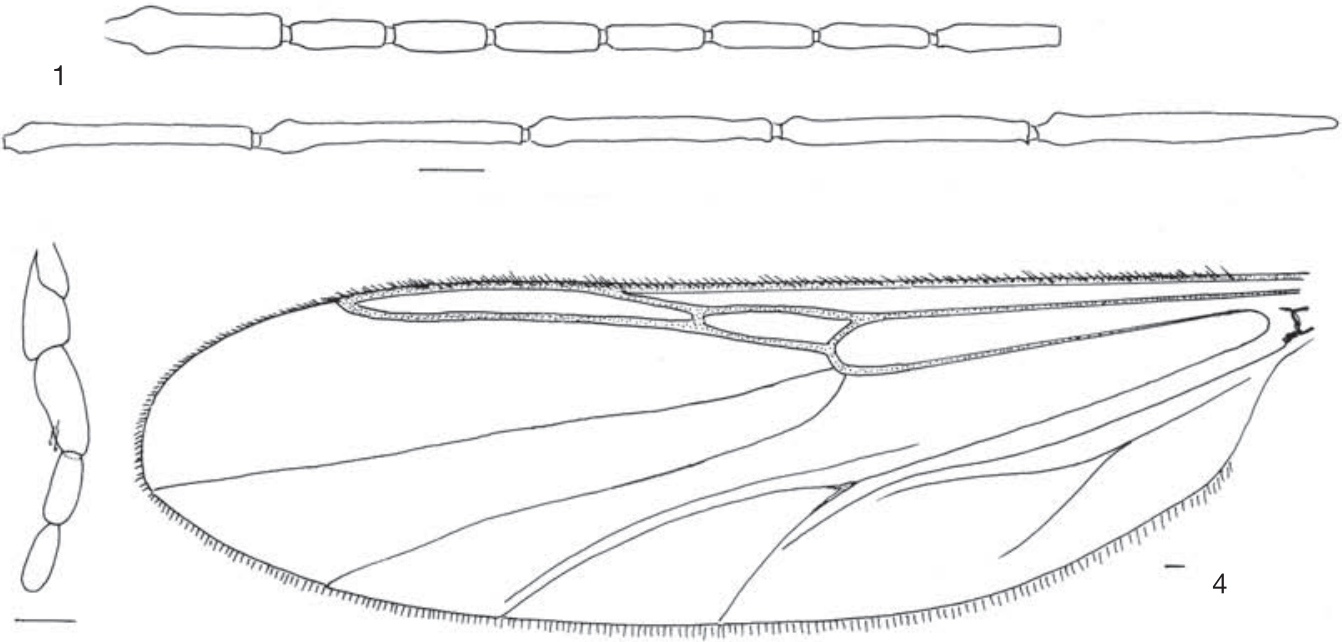

2

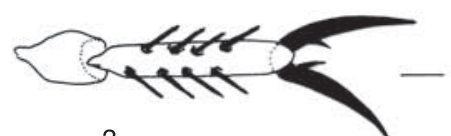

3
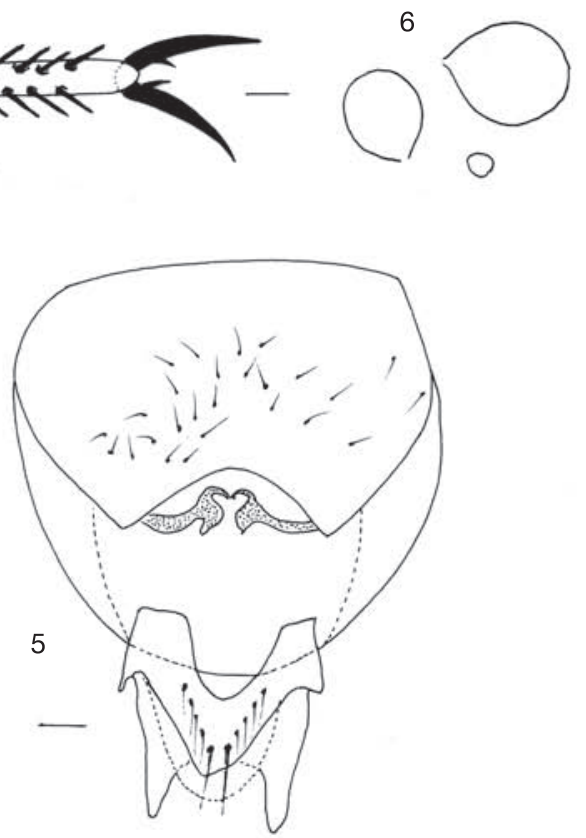
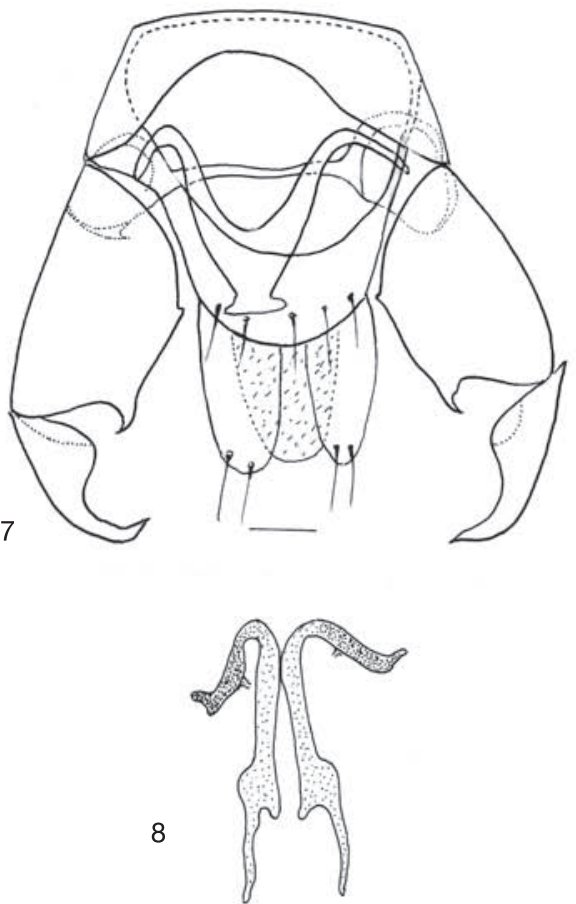

Fig. 1-8, Palpomyia iberaensis n.sp. 1-6 female; 7-8 male. 1; flagellum; 2; palpus; 3; fourth, fifth tarsomeres, and claws of fore leg; 4; wing; 5; abdominal segments 8-10; 6; spermathecae; 7; genitalia (parameres removed); 8; parameres (Scale bars $=0.05 \mathrm{~mm})$.

\section{DISCUSSION}

The female of $P$. iberaensis $n$. sp. fits in the tibialis group, although its curious male genitalia shows some characteristics that were not yet cited to it, such as: sternite nine with anterior margin straight; tergite nine with a concave anterior margin; gonocoxite with a conspicuous posteromesal pointed hook; gonostylus curved; and tip of parameres not recurved, posteriorly directed. 
By virtue of the fore and mid femora armed with ventral spines, this new species is similar to Palpomyia mellichroa Macfie 1939, a species only known from the holotype from Nova Teutonia, Santa Catarina, and Brazil. The holotype of $P$. mellichroa, a pinned female deposited in the Natural History Museum in London was recently examined by GRS and differs from $P$. iberaensis n. sp. by the five distal greatly elongated flagellomeres (AR 2.32), almost entirely yellowish brown legs and fore femur armed with 14 short, black spines.

\section{ACKNOWLEDGMENTS}

We acknowledge William L. Grogan for the review of an early version of the manuscript. Our gratitude is also extended to María del Carmen Coscarón, who collected the holotype. Carlos Lamas and Paul Hanson made appropriate suggestions acting as journal referees.

\section{RESUMEN}

Se describe Palpomyia iberaensis n. sp., recolectada con trampa Malaise en Corrientes, Argentina, con base en una hembra que traía adheridos los órganos genitales del macho. Se ubica la especie en el grupo tibialis a pesar de tener parameros con puntas curvadas. Se compara la especie con su congénere brasileño Palpomyia mellichroa.

Palabras clave: grupo Palpomyia tibialis, Palpomyia iberaensis n. sp., Diptera, Ceratopogonidae, taxonomía.

\section{REFERENCES}

Borkent, A. \& W.W. Wirth. 1997. World species of biting midges (Diptera: Ceratopogonidae). Bull. Amer. Mus. Nat. Hist. 233: 1-257.

Borkent, A. \& G.R. Spinelli. 2000. Catalog of the New World biting midges south of the United States of America (Diptera: Ceratopogonidae). Contrib. Entomol. Internat. 4: 1-107.

Grogan, W.L. \& W.W. Wirth. 1979. The North American predaceous midges of the genus Palpomyia Meigen (Diptera: Ceratopogonidae). Mem. Entomol. Soc. Wash. 8: 1-125.

Downes, J.A. \& W.W. Wirth. 1981. Ceratopogonidae, p. 393-421. In J.F. McAlpine, B.V. Peterson, G.E. Shewell, H.J. Teskey, J.R. Vockeroth \& D.M. Wood (eds.). Manual of Nearctic Diptera Vol. 1. Agriculture Canada Monograph 27. Ottawa, Canada.

Lane, J. 1960. Additional data on "Palpomyia” (Diptera, Ceratopogonidae). Rev. Bra. Biol. 20: 381-389. 